\title{
UNDERSTANDING HIDDEN FACTORS THAT INFLUENCE COSTS OF ARC WELDING OPERATIONS
}

\author{
Das S.* \\ *National Institute of Design (NID) \\ Paldi, Ahmedabad 380007, Gujarat, India \\ E-mail: Subirdas38@yahoo.com
}

\begin{abstract}
:
Manual metal arc welding is one of the most widely used metal joining processes in heavy engineering factories in the world and the estimation of welding-cost is critical as they need it to remain competitive in today's global economy. A number of studies have been carried out to find out different elements that dictate cost of welding. For most of the industrialized nations almost 85 percent of the total cost of welding is attributed to labor. Understanding the hidden factors that influence cost of welding can lead to a more productive welding operation and better bottom line profitability.

Aim of the present study is to evaluate the existing work methods adopted by the MMA welders to reduce the costs of MMA welding operations. Attempts have also been made to identify those hidden but dominant cost factors in welding operations responsible for significant cost reduction in labour and overhead, which usually remain overlooked.

Direct observation, activity recording and task analysis were carried out on randomly selected twenty four MMA welders during both morning and afternoon shifts where every single movement, necessary to perform each task in the welding process, was listed and the time taken to perform that movement was recorded. A number of 342 thrown away remnant electrodes were studied to get an idea about the wastage of electrode length.

The 8 hours' duty cycle of the MMA welders was divided into five main activities and different sub-activities. Study revealed the daily activities and time spent by the MMA welders in an 8 hours' work, where actual welding is happening only in $111.8+48.23$ minutes (on average), within which welders finish their work allotted for that day. Actual welding time is the combination of arc-on $(64.9+29.8$ minutes) and non arc-on time $(46.9+23.3$ minutes) which are around $13.5 \%$ and $9.8 \%$ of the 8 hours' duty respectively.

The non arc-on activities are again divided into different sub-activities under two broad headings - essential work activities (related to allotted work pieces) and auxiliary work activities (not related to allotted work pieces). Since a welder is paid mainly for the skill of fusing a joint and depositing weld metal, it is obviously essential to have a duty cycle as high as possible. But there is a limit, since the welder has to do other ancillary tasks.

The present study showed that without lengthening the net working time, the arc-on time could be increased to have more of duty cycle. This paper is to show where inefficiencies occur and thus where changes might be beneficial to reduce cost of welding. For example by reducing the time spent for cooling the hot electrode holder, by reducing the unnecessary extra time required for change of electrodes, by supplying electrodes within the easy reach of the MMA welders, by reducing the unnecessary wastage of working time due to a large number of hand movements with heavy welding screen or by utilizing maximum length of electrodes, etc. Ergonomics solutions have also been recommended to minimize the costs of arc welding operations.
\end{abstract}

Key Words: Manual Metal Arc Welding, Activity Analysis, Welding Cost 


\section{INTRODUCTION}

Manual metal arc welding is one of the most widely used metal joining processes in heavy engineering factory as well as in micro, small and medium enterprises under its manufacturing and service sectors. These are the vital segments of the Indian economy [1] in terms of its contribution to the country's industrial production, exports, employment and creation of an entrepreneurial base. Estimation of welding-cost is critical as most of the manufacturers struggle to remain competitive in today's global economy.

For industrialized nations like North America, Europe, and Japan, about 85 percent of the total cost of welding is attributed to labor, 9 percent to consumables (wire and gas), 4 percent to equipment, and 2 percent for power [2]. Labour makes up the largest portion of the cost, as much as $85 \%$ [3]. Therefore, to influence the total cost of welding significantly, it's important to focus on labour costs. Lyttle and Stapon [2] studied the role of right consumables to reduce welding cost and its impact on productivity and possible labour savings that counts. The fundamentals of welding cost determination were examined by Daune [4], whereas Masmoudi et al [5] tried to develop a cost estimation model of weld assemblages.

As a first step to introduce applications of ergonomics in MMA welding operations, Seminara and Peters [6] tried to expose the welding equipment manufacturers to the theory and objectives of human factors engineering with a view to improving their products, providing users with better welding equipment and saving in welding operations. Later on Eyestone [7] considered human factors engineering in welding machine design and made some modifications on the existing machine which was very easy to maintain and keep the MMA welding operation costs low. To provide more comfort to its operators and to reduce production costs, ergonomics and its application in welding were well established long back in 1978 [8]. Wolfram [9] applied Pre-determined Motion Time Study (PMTS) on the welders for estimating the work content and measuring the productivity. He developed a new method based on a simple statistical analysis of the times spent on various types of joints (fillets and butt welds) and the combination of data from each type of joints to produce a net time or cost for a structure made with the various joints of given lengths. A pilot study by the author [10] showed that in 8 hours' duty, MMA welders net working time was very less and most of time they could not utilize the maximum length of each electrode. It revealed that there is a need to look into the matter from ergonomics points of view and efforts should be implemented to improve operating factor. It is the percentage of time that a welder employs in actual arc-on time, with reference to the total time that the welder is physically present in the workplace [11]. Operator duty cycle is the amount of time an operator is actually welding versus time spent on related activities such as setup, cleanup, or other non-welding functions [2].

The present study aimed at evaluation of the existing work methods adopted by the MMA welders to reduce the costs of MMA welding operations. Attempts have been made to identify those hidden but dominant cost factors in welding operations responsible for significant cost reduction in labour and overhead, which usually remain overlooked.

\section{METHODS}

\subsection{Subjects}

Out of 82 male, experienced and typical arc welders, working on the production line in the different units of wagon and girder shops at a railway wagon manufacturing company in India, $54(65.8 \%)$ were randomly selected to act as volunteers for the present study. Out of these 54, only 24 (44.4\%) responded to the activity study. Physical characteristics, i.e., age, body weight, body height and BMl of each of the 24 arc welders were recorded. Welders' height and weight were recorded with Martin's anthropometer and weighing machine, respectively. 


\subsection{Direct observation, activity recording and task analysis}

To collect the necessary information and data with reference to their daily work, detailed activities of the randomly selected twenty four MMA welders were observed in working conditions during the morning and afternoon shifts and were recorded using the a modified method of Drury [12]. Each welder was asked to carry out their normal daily activities at normal pace using existing tools and implements, and wearing personal protective devices (PPDs) like work clothing, hand-held screen, hand gloves and safety shoes. The eight hours' duty of an MMA welder was divided into five main activities - time spent for the preparation of the job, time spent for the auxiliary activities after the completion of days work, actual working time, lunch and tea time and idle time. Each activity was again divided into subactivities. Every single movement, necessary to perform each task in the welding process, was listed and the time taken to perform that movement was recorded. Stress was given on the way of holding and mode of use of hand-held welding screens, electrodes and electrode holders. Total number of electrodes use, hand movements with the screen per shift and time spent for that was also recorded. Hanhart (made in Germany) 60 seconds stop watches were used for recording time and tally counter was used for movements, etc.

A number of 342 thrown away remnant electrodes were collected at random from the different shop floor area and their length were measured to get an idea about the length of electrode wastage. Data were also recorded from the Purchase and Store departments on the number of different sizes of electrodes received and consumed in one year and also the total amount spent for the same.

\section{RESULTS AND DISCUSSIONS}

Table I shows the distribution of 24 arc welders according to different units of wagon and girder workshops. The age and physical characteristics of arc welders are given in Table II, which shows that the subjects have more or less similar body structure as those of average Indians [13]. The average age of the MMA welders was $34.8 \pm 5.14$ years with a range of 27 to 45 years. The average years of experience of these welders are $11.1+4.02$ years with a range of 5 to 19.5 years. Table III shows the grouping of welders based on their age and work experience in arc welding. They are classified into three age groups - below 30 years, 30 to 40 years and 40 to 50 years having 4,15 and 5 welders, respectively. According to the years of experience, welders are divided into three groups -5 to 9 years, 10 to 14 years and 15 to 20 years of experience, with 10,9 and 5 welders, respectively. So among the subjects, more than $58 \%$ welders have more than 10 years of work experience in arc welding.

Table I: Distribution of arc welders $(\mathrm{N}=24)$ according to different units of the wagon and girder work-shops in a heavy engineering factory.

\begin{tabular}{|l|l|c|}
\hline Work-shop & \multicolumn{1}{|c|}{ Unit } & No. of welders \\
\hline \multirow{4}{*}{ Wagon } & Floor-running & 3 \\
\cline { 2 - 3 } & Under-frame welding & 2 \\
\cline { 2 - 3 } & Roof (air-pocket) welding & 5 \\
\cline { 2 - 3 } & Body-end & 6 \\
\hline \multirow{2}{*}{ Girder } & Railway slipper welding & 8 \\
\hline
\end{tabular}


Table II: Physical and physiological characteristics of arc welders $(\mathrm{N}=24)$.

\begin{tabular}{|l|c|c|c|}
\hline \multicolumn{1}{|c|}{ Parameters } & Mean & SD & Range \\
\hline Height $(\mathrm{cm})$ & 165.2 & \pm 2.99 & $160.2-171.0$ \\
\hline Weight $(\mathrm{kg})$ & 60.7 & \pm 6.63 & $50.5-71.5$ \\
\hline BMI $\left(\mathrm{kg} / \mathrm{m}^{2}\right)$ & 22.2 & \pm 2.16 & $19.2-27.8$ \\
\hline Age (years) & 34.8 & \pm 5.14 & $27.0-45.0$ \\
\hline Experience (years) & 11.1 & \pm 4.02 & $5-19.5$ \\
\hline
\end{tabular}

Table III: Grouping the welders based on their age and work experience in arc welding.

\begin{tabular}{|l|c|c|c|}
\hline \multirow{2}{*}{} & \multicolumn{3}{|c|}{ Age } \\
\cline { 2 - 4 } & Below 30 years & $30-40$ years & $40-50$ years \\
\hline $\begin{array}{l}\text { Number and } \\
\text { percentage } \\
\text { of subjects }\end{array}$ & $4(16.7 \%)$ & $15(62.5 \%)$ & $5(20.8 \%)$ \\
\hline \multirow{3}{|c|}{ Experience } \\
\cline { 2 - 4 } & 5 yrs. -9 yrs. & 10 yrs. - 14 yrs. & 15 yrs. - 20 yrs. \\
\hline $\begin{array}{l}\text { Number and } \\
\text { percentage } \\
\text { of subjects }\end{array}$ & $10(41.7 \%)$ & $9(37.5 \%)$ & $5(20.8 \%)$ \\
\hline
\end{tabular}

All the welders work six days a week and 8 hours a day with a break of 45 minutes for lunch and 2 breaks of 15 minutes each for tea. Total time spent in different activities is shown in Table IV, whereas daily activities and related time spent in percentage of 8 hours' duty of an MMA welders is shown in Fig.1. It shows that the actual welding is happening only in $111.8 \pm$ 48.23 minutes (on average) with the range from 32 to 210 minutes, within which they finish their work allotted for that day. The wide variations in actual welding time depend on the work allotted for that day and also on the type of work which again varied widely in different workshops and also in different units of the same workshop as observed and presented Table $\mathrm{V}$. Actual welding time is again divided into arc-on time and non arc-on time. In the present scenario, these are around $13.5 \%$ and $9.8 \%$ of the 8 hours' duty, respectively. The wide variations in the net arc-on time depend on the type of welding allotted for that day and the extent of welding carried out in that day. The arc-on time also depends on the type of work, the site to be welded and the amount of electric current used and the age as well as the skill [14] of the welders. 
Table IV: Daily activities and time spent by the MMA welders in an 8 hours' work.

\begin{tabular}{|c|c|}
\hline Activities and time spent in minutes & Sub-activities \\
\hline $\begin{array}{l}\text { 1. Preparation for the job } \\
{ }^{*} 98.9 \pm 10.55(80-125) \\
{ }^{* *} 20.6 \pm 2.19(16.7-26.1)\end{array}$ & $\begin{array}{l}\text { i) Change clothes, i.e., dress themselves with } \\
\text { existing personal protective devices (PPDs)ii) } \\
\text { iii) Wait for the allocation of day's work } \\
\text { iv) Receive oral instruction on the day's work } \\
\text { v) Collect electrodes from the store }\end{array}$ \\
\hline $\begin{array}{l}\text { 2. Auxiliary activities after completion } \\
\text { of day's work } \\
{ }^{*} 64.5 \pm 4.84(60-70) \\
* * 13.4 \pm 1.01(12.5-14.6)\end{array}$ & $\begin{array}{l}\text { i) Welders arrange their PPDs, tools and } \\
\text { implements into their personal cupboard } \\
\text { ii) Return extra electrodes (if not consumed) to } \\
\text { the stores } \\
\text { iii) Remove the boiler suit } \\
\text { iv) Take a bath } \\
\text { v) Dress themselves with their usual cloths }\end{array}$ \\
\hline $\begin{array}{l}\text { 3. Actual Welding Activity } \\
* 111.8 \pm 48.23(32-210) \\
* * 23.3 \pm 10.05(6.6-43.7) \\
\text { a) Arc-on Activity } \\
* 64.9 \pm 29.78(21.1-126.3) \\
* * 13.5 \pm 6.21(4.4-26.3) \\
\text { b) Non arc-on Activities } \\
* 46.9 \pm 23.33(10.9-98.4) \\
* * 9.8 \pm 4.86(2.3-20.5)\end{array}$ & $\begin{array}{l}\text { i) Essential work activities (related to allotted } \\
\text { work-piece) } \\
\text { ii) Auxiliary work activities (not related to } \\
\text { allotted work-piece) }\end{array}$ \\
\hline $\begin{array}{l}\text { 4. Breaks } \\
\text { a) Lunch break } \\
{ }^{*} 43.9 \pm 7.38(30-60) \\
{ }^{*} 9.2 \pm 1.54(6.3-12.5) \\
\text { b) Tea break } \\
{ }^{*} 17.7 \pm 4.91(10-30) \\
{ }^{*} 3.7 \pm 1.02(2.1-6.3)\end{array}$ & i) One lunch-break for one hour \\
\hline $\begin{array}{l}\text { 5. Other Activities } \\
{ }^{*} 143.2 \pm 44.57(60-120) \\
* * 29.8 \pm 9.28(12.5-43.7)\end{array}$ & $\begin{array}{l}\text { i) Gossip } \\
\text { ii) Rest, sleep, etc. } \\
\text { iii) Attending the toilet, etc. }\end{array}$ \\
\hline
\end{tabular}

[Data: Mean \pm SD (Range); In minutes; ${ }^{* *}$ In percentage of 8 hours' work] 


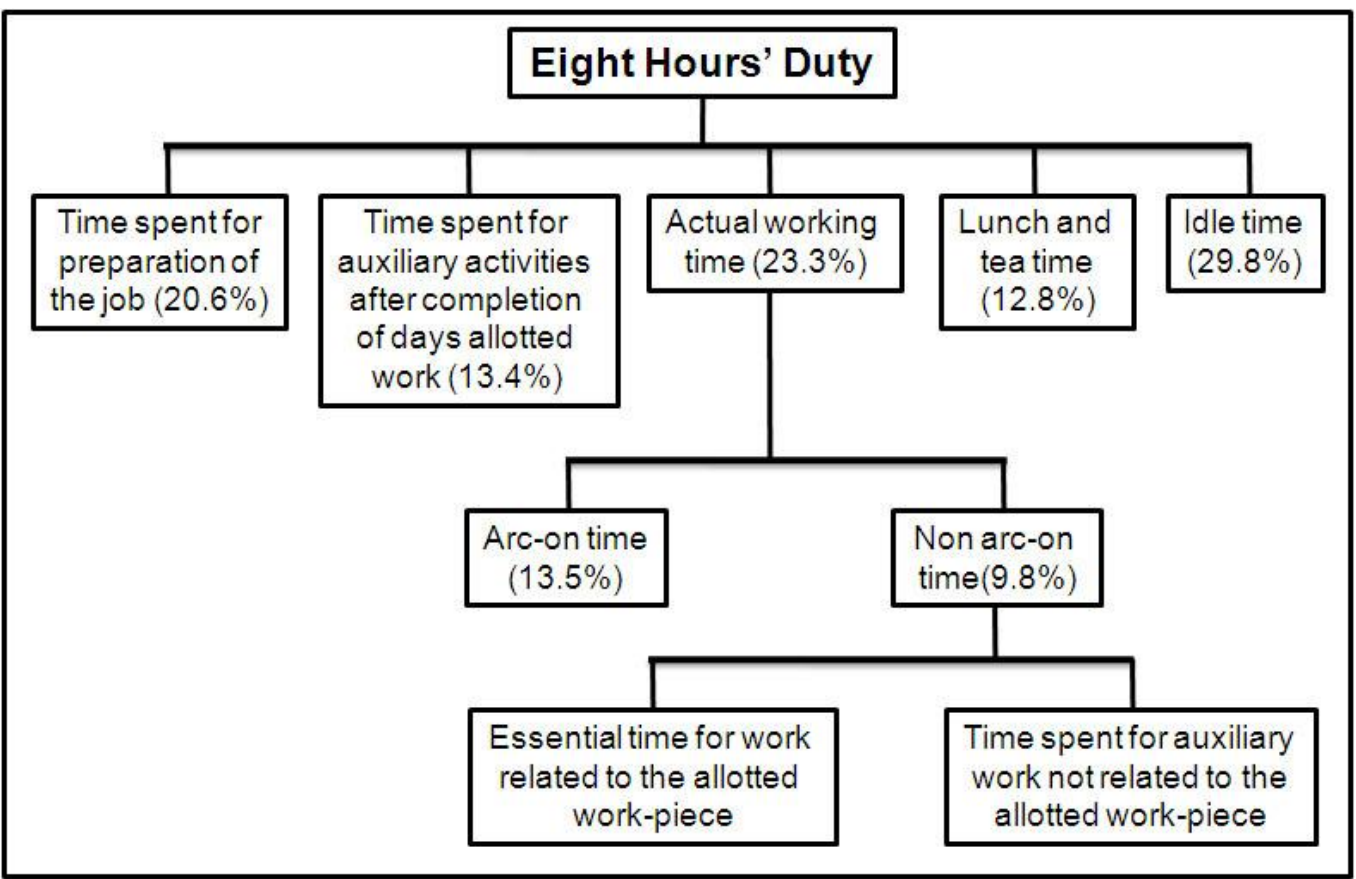

Figure 1: Daily activities and related time spent in percentage of 8 hours' duty of an MMA welder.

Table V: Comparison of actual welding time in different units of the wagon and girder shops [Data: Mean \pm SD (Range)]

\begin{tabular}{|c|l|c|c|}
\hline \multirow{2}{*}{$\begin{array}{c}\text { Work- } \\
\text { shop }\end{array}$} & \multicolumn{1}{|c|}{ Different units } & \multicolumn{2}{|c|}{ Actual welding time } \\
\cline { 2 - 4 } & & In minutes & In \% of 8 hours' work \\
\hline \multirow{4}{*}{ Wagon } & Roof welding & $47.7 \pm 10.91$ & $9.9 \pm 2.27$ \\
& & $(32-57)$ & $(6.7-11.9)$ \\
\cline { 2 - 4 } & Body end & $(64.0 \pm 31.51$ & $20 \pm 6.56$ \\
& & $122.7 \pm 12.22$ & $(13.3-26.5)$ \\
\cline { 2 - 4 } & Floor-running & $(112-136)$ & $25.6 \pm 2.55$ \\
& & $205 \pm 7.07$ & $(23.4-28.4)$ \\
\cline { 2 - 4 } & Under-frame welding & $(200-210)$ & $(41.7 \pm 1.47$ \\
& & $116.6 \pm 13.43$ & $24.3 \pm 2.79$ \\
\hline Girder & Railway sleeper & $(93-125)$ & $(19.4-26.1)$ \\
& welding & $111.8 \pm 48.23$ & $23.3 \pm 10.05$ \\
\hline \multicolumn{2}{|c|}{ For all workshops } & $(32-210)$ & $(6.6-43.7)$ \\
\cline { 2 - 4 }
\end{tabular}

The non arc-on activities are again divided into different sub-activities under two broad headings -

a) Essential work activities (related to allotted work pieces):

i) Connecting the work (to be welded), metal (to be earthed) and electrode holder to the welding machine through the cables; turning the knob of the welding unit to the desired amperage required for that specific job;

ii) Fixing the work-pieces to the fixture or jig with the help of a helper;

iii) Cleaning or degreasing the work surface by using a steel brush or by spraying the degreasing chemical solutions;

iv) Fixing electrode to the holder at a desired angle;

v) Removing the red hot remnant electrodes from the holder;

vi) De-slagging by using a chipping hammer and a steel brush; 
b) Auxiliary work activities (not related to allotted work pieces):

i)Carrying and repetitively moving the hand-held welding screen in and out in front of the face:

ii) Repetitively keeping on the ground and picking up the hand-held welding screen to protect their eyes and faces from the UV and thermal radiations, sparks and hazardous fumes coming from the arc;

iii) Waiting to cool down the hot electrode holder sufficiently to hold and work with it;

iv) Wrapping waste paper or torn clothes around the handle of the hot electrode holder to protect the palm;

v) Sometime holding it under the running tap-water to cool it completely.

The essential components of the total costs of an MMA welding operation can be divided into - a) Labour charge for the welders; b) Associated labour charges for helpers; c) Costs of accidents and personal protective devices (PPDs) used; d) Costs of electrodes; e) Costs of electric power; f) Costs (capital) for machines, ancillary tools and equipment and the depreciation costs; g) Costs for maintenance and repairs; and h) Costs for quality control, designing, storage, sales and general administration. Application of ergonomics principles could effectively reduce the costs of most of the above mentioned elements as discussed below:

\subsection{Labour charge for the welders}

Every MMA welder is paid for his eight hours' duty. Besides arcing, he has to do a number of other essential works within this period as shown in Table IV. From the total arcing time of an MMA welder, his duty cycle (defined as the arcing time expressed as a percentage of total time) can be calculated [15] as follows:

$$
\text { Duty cycle }=[\text { Total arcing time } / \text { Total time }] \times 100(\%)
$$

Since a welder is paid principally for the skill of fusing a joint and depositing weld metal, it is obviously essential to have a duty cycle as high as possible. But there is a limit, since the welder has to do other ancillary tasks.

The present study has revealed that without lengthening the actual working time $(111.8 \pm 48.23$ minutes) the arc-on time, which is only $13.5 \%$ of the total eight hours' duty, can be increased by decreasing the non arc-on time, spent for the auxiliary work activities, which are not related to the allotted work pieces and hence is non-productive time. It is around $9.8 \%$ of 8 hours' duty and on average $46.9 \pm 23.3$ minutes. Possible areas where we can save time are mentioned below.

(i) By reducing the time spent for cooling the hot electrode holder: Mainly because of the bad design of the existing electrode holder and also due to the use of aluminum cables in place of the copper cables, it becomes very hot within a few minutes of work [16]. Sometimes, it caused blisters on their hands. As a result, the MMA welders frequently stop their work and try to cool it either by waiting for a few minutes, or by wrapping with several empty paper packets of the electrodes or torn clothes around the handle or by holding it under the running tap-water resulting in a loss of valuable working time. Moreover, the use of water damages the MMA electrode holder and at the same time increases the chances of severe accidents.

(ii) By reducing the unnecessary extra time required for changing of the electrode: At present, welder has to spend unnecessarily more time to fix the electrodes to it at any desired angle and also to remove the red hot remnant electrodes from the holder. In some cases, remnant electrodes melt and stuck to the holder and the welder has to remove it either with the help of another electrode or by hitting the holder against any solid object which in most of the cases damage the electrode as well as the holder and also resulted in the wastage of valuable work time. 
(iii) By supplying electrodes within the easy reach of the MMA welders: Usually arc welders collect, on an average of about $45 \pm 20$ electrodes (Table $\mathrm{VI}$ ), weighing approximately $2.25 \mathrm{~kg}$ for $4 \mathrm{~mm}$ and $5.78 \mathrm{~kg}$ for $5 \mathrm{~mm}$ electrodes from the store during the start of the days' work.

Table VI: Total number of electrodes used, total number of hand movements and daily wastage of working time of each MMA welder in 8 hours' duty due to large number of hand movements with the hand-held welding screen.

\begin{tabular}{|c|c|c|c|c|}
\hline & \multicolumn{3}{|c|}{ Values } \\
\hline & & Mean & SD & Range \\
\hline \multicolumn{2}{|c|}{$\begin{array}{l}\text { Total number of electrodes } \\
\text { used/shift }\end{array}$} & 45 & 20 & $(14-77)$ \\
\hline \multicolumn{2}{|c|}{ Total Number of hand movements } & 385 & 190 & $(134-858)$ \\
\hline \multirow{2}{*}{$\begin{array}{l}\text { Wastage of } \\
\text { working time }\end{array}$} & In minutes & 3.21 & 1.58 & $(1.12-7.15)$ \\
\hline & In percentage & 3.02 & 1.12 & $(1.65-5.43)$ \\
\hline
\end{tabular}

They have to carry and move it from place to place causing unnecessary static work of the hand and fingers and resultant fatigue. Most of the times sweat of the palm damages the electrodes particularly during summer months.

It has been observed that in most of the cases, the welders have to waste his working time to find out where he has kept the electrodes. A large number of electrodes are either damaged or lost, during carrying within the workshops. This loss of electrodes can easily be saved by using specially designed work-clothing with the long pockets, on the right back of body, similar to an arrow-holder and on the left leg, of an archer, resulting in an easy and quick supply and handling of the electrodes during work and thereby, would also be able to reduce the unnecessary wastage of electrodes and working time.

(iv) By reducing the unnecessary wastage of working time due to a large number of hand movements with the heavy welding screen: During work, welders protect their eyes and face from the uv and thermal radiations by bringing the welding screen, hold by left hand, in front of the face. The frequency of movements of the left hand with the welding screen in each welder varies from 134 to 858 with an average of $385 \pm 190$ during the total working period of about $111.8 \pm 48.23$ minutes. The wide range of hand movements per electrode depends on the type of work and the site of welding. The total time required for these large number of hand movements range from 1.12 to 7.15 minutes with an average of $3.21 \pm 1.58$ minutes as shown in Table VI. Therefore, this large number of unnecessary hand movements took away 1.65 to $5.43 \%$ of each welder's actual working time of about 111.8 minutes with an average of $3.02 \pm 1.12 \%$. This wastage of the part of the non arc-on time could be saved by using welding screens fitted to the head and with photo-chromatic welding glasses. In existing scenario, after a few minutes of work, the welders feel severe pain in their left/right hands for these large numbers of hand movements as well as for the unnecessary continuous carrying of the heavy welding screens weighing about 1.5 to $2.25 \mathrm{~kg}$. In each shift, total time spent by each welder in unnecessary holding and carrying of the hand-held welding screen is presented in Table VII. All these ultimately slowed down the pace of work. 
Table VII: Time spent in unnecessary holding and carrying of the hand-held welding screen by each MMA welder [Data: Mean \pm SD (Range)].

\begin{tabular}{|c|c|c|}
\hline \multicolumn{2}{|c|}{ Time spent in unnecessary holding \& carrying of the screen } \\
\hline In minutes & $\begin{array}{c}\text { In percentage of } \\
\text { actual working time }\end{array}$ & $\begin{array}{c}\text { In percentage of } \\
8 \text { hours' duty }\end{array}$ \\
\hline $87.7 \pm 37.95$ & $78.9 \pm 11.05$ & $18.3 \pm 7.90$ \\
$(28-155)$ & $(47.43-96.25)$ & $(5.89-32.29)$ \\
\hline
\end{tabular}

\subsection{Associated labour charges for the helpers}

Occasionally the MMA welders are helped (for fixing the work pieces to the jig or fixture, etc.) by another person (helper) to complete their task quickly and satisfactorily. The increased costs resulting from the use of additional labour must be taken into account. Nothing could be done in this case unless some special jigs or devices are used.

\subsection{Costs of accidents and PPDs used by the MMA welders}

Foster [11] has pointed out that $7 \%$ of around 90,000 annually reported eye injuries are caused by intense light or radiating substances and $95 \%$ of these are identified as welder's flash. During 1985 , welders submitted $21 \%$ of all claims for eye injuries received by the "Worker's Compensation Board" of Alberta, USA [12]. The amount of the money spent for the personal protection of the MMA welders, are not very effective and useful since the existing PPDs are unable to save the welders from a number of heat burn and other injuries and thereby, resulting in an increase of costs of accidents. Proper selection of ergonomically designed, low-cost, special type of welding screen, work clothing, safety shoes and hand gloves would be able to reduce this large number of heat burns and other injuries and thereby would save a considerable amount of money spent as costs of accidents.

\subsection{Costs of electrodes}

The quantity of the electrodes required was the main cost of consumables. Present study shows that about Rs. 8.2 million is spent for approximately 9,64,750 electrodes consumed in one year (Table VIII). Due to the bad design of the existing electrode holders, the MMA welders could not utilize the maximum length of the electrodes and thereby, resulted in wastage on an average $9.1+6.11 \mathrm{~cm}$ length of each electrode with a range of 2.6 to $35.6 \mathrm{~cm}$. In percentage, it is around $21.09+14.22 \%$ of the length of each electrode with a range of 6.1 to $82.8 \%$ (Table IX). Even a $10 \%$ saving of this wastage would mean an average the financial saving of the electrode cost of about Rupees 0.2 million per annum for the factory where the study was undertaken.

Table VIII: Numbers of different sizes of electrodes received and issued (consumed) in one year and the total amount spent for the same.

\begin{tabular}{|c|c|c|c|}
\hline \multicolumn{4}{|c|}{ Electrodes } \\
\hline Diameter $(\mathrm{mm})$ & Length $(\mathrm{cm})$ & Received & Consumed \\
\hline 5.00 & 45 & $5,48,800$ & $4,85,700$ \\
\hline 4.00 & 45 & $4,35,050$ & $3,75,100$ \\
\hline 3.15 & 45 & $1,25,800$ & 45,950 \\
\hline 2.50 & 35 & 60,000 & 58,000 \\
\hline \multicolumn{2}{|c|}{ Total number of electrodes } & $11,69,650$ & $9,64,750$ \\
\hline \multicolumn{2}{|r}{ Total amount spent in million rupees } & 8.73 & 8.20 \\
\hline
\end{tabular}


Table IX: Wastage of length of each electrode due to its non-utilisation [Data: Mean \pm SD (Range)].

\begin{tabular}{|c|c|c|c|}
\hline $\begin{array}{l}\text { Number of electrodes } \\
\text { studied }\end{array}$ & $\begin{array}{c}\text { Initial length } \\
(\mathrm{cm})\end{array}$ & Final length $(\mathrm{cm})$ & Wastage (\%) \\
\hline 342 & 43.0 & $9.1 \pm 6.11$ & $21.09 \pm 14.22$ \\
& & $(2.6-35.6)$ & $(6.1-82.8)$ \\
\hline
\end{tabular}

The existing traditional holders resulted in poor visibility of electrode-tips, particularly when these become shorter, affecting quality as well as quantity of welding [16]. To increase visibility, sometimes the MMA welders bend the tip of electrodes and in the process, damage it. Moreover, in existing holders, there is no provision of protection of the welders' hands from the thermal radiations coming from the red hot electrodes and also from the arc. As the electrode becomes shorter, the holder also becomes intensely hot. As a result, the welders throw away these electrodes before utilizing its maximum length.

\subsection{Costs of electric power}

In most of the cases, the MMA welders use more than the specified amount of current (as printed on the box-cover of the electrodes) for quick completion of the day's work schedule. This not only deteriorates the quality of welding, but also makes the holder and the transformer too hot to work with. This should be checked immediately to reduce the cost of electric power.

\subsection{Capital costs of machines, ancillary tools and equipment}

Before selection, purchase and installation of the MMA welding machines, tools and equipment, ergonomic points should be considered or an ergonomist should be consulted for better selection of the above mentioned items to reduce the incidental costs.

\subsection{Costs of maintenance}

It is the amounts of money spend to keep the welding plant including machines, tools and equipment, in good condition. Some of the main important ergonomic steps that could immediately be considered to reduce the maintenance costs are given below:

i) Use of more than specified amount of electric current makes the electrode holder and the transformer too hot to be damaged quickly resulting in increase of costs of maintenance. Use of specified current could save this cost easily.

ii) The thrown out red hot electrode-stubs not only damages the welding cables but also the shoes of the welders and other workers working near by, resulting in an increase of maintenance costs of the cables and the safety shoes. In some cases, these thrown-away remnant electrodes are used to fill the small gaps between the parts to be welded. Therefore during its requirement welders has to search out the thrownaway remnant electrodes of specific sizes. This cost of maintenance and the time for collecting the electrode stubs in a sandbox instead of throwing them away could easily save their search.

iii) It is also very essential to train the MMA welders about the careful handling of all the related machines, tools and equipment to reduce the costs of maintenance.

\subsection{Costs for quality control, design, stores, sales and general administration}

In the present study, no stress has been given on these aspects. Application of new, ergonomically designed, low-cost personal protective devices and ancillary tools and equipment would be able to reduce a large number of hazards faced daily by the MMA 
welders and thus would increase the skill as well as the quality of welding. This would also have a beneficial effect on the reduction of the costs of welding.

\section{CONCLUSION}

The present study showed that without lengthening the net working time, the arc-on time could be increased to have more of duty cycle. This paper also explained where inefficiencies occur and thus where changes might be beneficial to reduce cost of arc welding.

As labour makes up the largest portion of the cost [3] it is important to focus on their involvement and activities in the whole process to influence significantly the total cost of welding. Since a welder is paid principally for the skill of fusing a joint and depositing weld metal, it is obviously essential to have a duty cycle as high as possible. Present study also showed us directions for redesigning the existing electrode holders, welding screens and work clothing which will ultimately affect the duty cycle of arc welders by reducing the non arc-on time spent for the auxiliary non-productive work activities not related to the allotted work pieces. The quantity of electrodes required is the main cost of consumables. Use of a newly designed electrode holder would make it possible to utilise the maximum length of each of the electrodes leading to its minimum wastage.

\section{ACKNOWLEDGEMENTS}

The authors are very much grateful to all MMA welders for their kind cooperation during the data collection and in the field studies.

\section{REFERENCES}

[1] Government of India. (2007). Small Scale Industries: Annual Report 2006-2007. Ministry of Small Scale Industries, New Delhi

[2] Lyttle, K. A. and Stapon, W.F.G. (1997). Choosing the right consumables to reduce welding cost, Practical Welding Today, September/October issue

[3] Cording, W. (2002). Go with the flow - how shielding gas affects welds' productivity, Practical Welding Today, November/ December issue

[4] Daune, K. M. (2004). Determining the cost of welding, Welding Design \& Fabrication (http://weldingdesign.com/processes/news/wdf_10760/, accessed on 23-06-2011)

[5] Masmoudi, F., Hachocha, W. and Bouaziz, Z. (2007). Development of a welding cost estimation model based on the feature concept, Advanced in Production Engineering \& Management, Vol.2, No.4, 149-162

[6] Seminara, J. L. and Peters, G. A. 1958. Research in human engineering aids design, Industrial Laboratories, May, 20-21

[7] Eyestone, J. D. 1971. Human factors engineering in welding machine design, Welding Journal, Vol. 50, 168-173

[8] Corlett, E.N. and Bishop, R.P (1978). The ergonomics of spot welders, Applied Ergonomics, Vol. 9, No.1, 23-32

[9] Wolfram, J. 1979. Estimating work content and measuring productivity. Metal Construction, Vol. 11, 121-124

[10] Sen, R. N. and Das, S. 1993. Ergonomics, occupational health and safety improvements for the manual metal arc welders, Sen, R. N.; Das, S. and H. P. Chattopadhaya (Editors), Occupational and Environmental Ergonomics, Indian Society of Ergonomics, Calcutta, 97-102

[11] Welding Handbook (2001). Economics of Welding and Cutting, Welding Science and Technology, Welding Handbook, 9th Ed., Vol. 1, American Welding Society

[12] Drury, C. G. 1990. Methods for direct observation for performance, Wilson, J. R. and Corlett, E. N. (Editors), Evaluation of human work, Taylor and Francis, $35-37$

[13] Chakrabarti, D. 1993. Indian anthropometric dimensions for ergonomic design practice, National Institute of Design, Ahmedabad 
[14] Sen., R. N., Das, S. and Sahu, S. 1995. Ergonomic evaluation of work-load and workenvironment of the middle-aged and older workers in India. Kumashiro, M. (Editor), The Paths to Productive Aging, Taylor and Francis, London, 261-267

[15] Gourd, L. M. 1986. Principles of welding technology, The Welding Institute, English Language Book Society/Edward Arnold Publishers Ltd., London

[16] Das, S. 2004. Design Evaluation of Existing Electrode Holders Used by the MMA Welders. Proceedings of the National Conference on Humanizing Work and Work Environment (HWWE - 2004), 137-142

[17] Foster, R. 1988. Industrial eye safety - a sensible approach, Welding Journal, Vol. 67, 71-74

[18] Reesal, M. R., Dufresne, R. M., Suggett, D. and Alleyne, B. C. 1989. Welder's eye injuries. Journal of Occupational Medicine, Vol. 31, 1003-1006 